\title{
Editorial
}

\section{Parents of Multiples and Decision-Making}

\section{George A. Little, MD}

Journal of Perinatology (2004) 24, 2-3. doi:10.1038/sj.jp.7211024

In this journal, parents of multiple births have added their perspective on decision-making in the neonatal intensive care unit (NICU). ${ }^{1}$ All who care for neonates should thank the author for communicating new information, wisdom and practical points. For example, while most know the importance of photographs to parents, are we as aware of the meaning of having photographs of multiples together even if extreme duress or death is present? I was not.

This study joins a history of parental communication that spans more than 3 decades and includes books, press and electronic media releases, parent and professional committee statements and studies in peer-reviewed literature. Some books discuss the experience of being a NICU parent and decision-making in a positive and appreciative or supportive manner, while others are more questioning or critical. ${ }^{2-4}$ As uncomfortable as it may be, reading The Long Dying of Baby Andrew is as meaningful today as it was in 1983 .

The reviewers and editor recognized this study for its parental contributions and endorsed publication with the editor requesting this commentary. Parents have not always felt as welcomed in their efforts to communicate in the medical literature. The publication in Pediatrics of The Principles of Family-Centered Neonatal Care in $1993^{5}$ was done without peer review and with the anticipation of controversy following an executive decision by the Editor, explained in an editorial. ${ }^{6}$

As with any study, one can list concerns. It is experiential and opportunistic; there is no control or comparative population; it has a long timeline (late 1980s to 2001); demographic data were not "systematically collected" and the study cohort is relatively small. Furthermore, the style of the manuscript is different from most. On the other hand, the population — parents of multiples — is unique and increasing in size, the survey methodology is innovative, including its use of the Internet, and qualitative research techniques were employed. Qualitative research includes the capability for revision of study questions or hypotheses as accumulation of observations progresses, thereby allowing for collection of new data. Study of specific pediatric populations using

Department of Pediatrics and Obstetrics and Gynecology, Children's Hospital at Dartmouth, Lebanon, NH, USA..

Address correspondence and reprint requests to George A. Little, MD, Department of Pediatrics and Obstetrics and Gynecology, Children's Hospital at Dartmouth, Lebanon, NH 03756, USA. qualitative techniques has provided valuable contributions, including insight into the situation of siblings of children with chronic diseases such as cystic fibrosis or leukemia. ${ }^{7}$ With the evolution of increasing qualitative focus and rigor, we can anticipate and support more publications of this type.

What emerges is that while parents of multiples have some unique aspects in the decision-making and bereavement part of their experience, overall there is great similarity to their singleton compatriots. We must recognize the unique aspects or we will not meet the needs of the smaller, albeit growing, multiples population. We must also integrate the message from the multiples into the total birth cohort to expand our understanding and ability to change and improve practice. In general, younger perinatal care providers have had less direct experience with decision-making and bereavement in both their personal and professional lives and to some extent stand to benefit most from the experience and lessons of parents who have.

The fact that $18 \%$ of parents report criticism about medical care decisions, including resuscitation, is bothersome. Their experience is blemished. While some of the examples provided involve very difficult and emotion-laden decisions that occur prepartum, including reduction of multiple gestation, the significance of this finding should not be minimized. The literature documents that in addition to the usual differences in knowledge, beliefs and values that occur among individuals and groups, there are consistent differences and tensions among and between parents and providers in the perception and valuing of quality of life. ${ }^{8}$ Neonatal physicians and nurses appear to be more concerned about what they perceive to be risk of poor outcome than parents. ${ }^{9}$ I like to think that far fewer than 1 in five of my patients experienced or perceived criticism about their care decisions, but I do not actually know.

Perinatal medicine has committed itself to improving outcomes. ${ }^{10,11}$ Parental satisfaction is a legitimate and important value, along with function, outcome, and cost. ${ }^{12}$ As seen in the paper under discussion, parents remember and express the importance to them of qualities such as collaboration, degree of directiveness, and support, as well as immediate issues such as method of communication, time, and timing. Communication and processes that function well are essential to the development and maintenance of trust. Transparency, an ethical principle, ${ }^{13}$ provides not only a foundation for collaboration with parents but also provides guidance to how communication and process should be openly conducted to improve quality and outcomes of all pregnancies, single and multiple.

Finally, let us acknowledge that this publication originates from a sole researcher and author who related to me that she is a parent 
of twins, one of whom was stillborn and the other is a NICU graduate (she reviewed this paragraph prior to publication). Dr. Pector's interest in multiples arose from that experience. She is a family practitioner in a middle American community and received no funding for her study. She does not have a formal academic role or appointment at present. She makes an appropriate case that although institutional review board approval was not sought, the principles of that process were met. The wisdom she offers comes from a labor of concern and love.

\section{References}

1. Pector EA. Views of bereaved multiple-birth parents on life support decisions, the dying process, and discussions surrounding death. 2004; 24(1):4-10.

2. Smith T. Miracle Birth Stories of Very Premature Babies. Westport and London: Bergin and Garvey; 1999.

3. Mehren E. Born Too Soon. New York, NY: Doubleday; 1991.

4. Stinson S, Stinson P. The Long Dying of Baby Andrew. Boston, MA: AtlanticLittle Brown; 1983.
5. Harrison H. The principles of family-centered neonatal care. Pediatrics 1993;92:643-50.

6. Lucey JF. Parental dissatisfaction with neonatal intensive care unit care and suggestions for improvements. Pediatrics 1993;92:724.

7. Fanos JH. Sibling Loss. Mahwah, NH: Lawrence Erlbaum Associates; 1996.

8. Harrison H. Making lemonade: a parent's view of "quality of life" studies. J Clin Ethics 2001;12(3):239-250.

9. Saigal S, Stoskopf BL, Feeny D et al. Differences in preferences for neonatal outcomes among health care professionals, parents, and adolescents. JAMA 1999;281:1991-7.

10. Committee on Perinatal Health. Toward Improving the Outcome of Pregnancy. White Plains, NY: National Foundation March of Dimes; 1976.

11. Committee on Perinatal Health. Toward Improving the Outcome of Pregnancy: The 90s and Beyond. White Plains, NY: National Foundation March of Dimes; 1993.

12. Conner JM, Nelson EC. Neonatal intensive care: satisfaction measured from a parent's perspective. Pediatrics 1999;103(1):336-49.

13. King NMP. Transparency in neonatal intensive care. Hastings Center Report. May-June: 18-25, 1992. 